\title{
A Nova Velhice Do Provedor
}

\author{
Nivia Cardoso Guirra Santana ${ }^{1}$ \\ e Isabel Maria Sampaio Oliveira Lima²
}

\begin{abstract}
RESUMO
A longevidade e a melhora da qualidade de vida da população idosa produziram reflexos em diversos setores da sociedade, inclusive nas formações familiares. A imagem dos idosos como dependentes, passa a ser relativizada por outras imagens que afirmam o papel do idoso participativo no âmbito social, econômico e afetivo. 0 objetivo do presente estudo é discutir 0 papel do idoso na sociedade contemporânea enquanto protetor da infância. A estratégia metodológica adotada foi de natureza qualitativa, com revisão de literatura e utilização dos dados do Instituto Brasileiro de Geografia e Estatística (CENSO, PNAD e PEA). Os resultados indicam que, não obstante a importância do tema, tímida é a produção científica brasileira a respeito da guarda de crianças e adolescentes por seus avós, entendida como mecanismo de proteção infantil desenvolvido nas relações familiares intergeracionais.
\end{abstract}

Palavras-chave: Idoso. Criança. Guarda. Proteção social.

\section{THE NEW OLD AGE OF THE PROVIDER}

\begin{abstract}
Longevity and the improved quality of life of the elderly population reflected in various sectors of society, including family formations. The image of elderly people as dependents is switched to other images that affirm the role of the elderly participating in the social, economic and affective spheres. The aim of this study is to discuss the role of the elderly in contemporary society as protector of childhood. The methodology adopted was qualitative in nature, with review of literature and use of data from the Brazilian Institute of Geography and Statistics (CENSUS, PNAD and PEA). The results indicate that, despite the importance of

\footnotetext{
${ }^{1}$ Mestre em Família na Sociedade Contemporânea pela Universidade Católica do Salvador, Brasil. nivia@silveiraguirra.com.br

${ }^{2}$ Juíza de Direito e Docente da Universidade Católica do Salvador, Brasil. isabelmsol@gmail.com
} 
the subject, the Brazilian scientific production on the care of children and adolescents by their grandparents, understood as a child protection mechanism developed in intergenerational family relationships, is scant.

Keywords: Elderly. Child. Custody. Social protection.

objetivo do presente estudo é discutir o papel do idoso na contemporaneidade e
suas relações desenvolvidas com netos na ausência, simbólica ou real, da
geração-meio.

A longevidade e a melhora da qualidade de vida da população idosa produziram reflexos em diversos setores da sociedade, inclusive nas formações familiares. A imagem dos idosos como dependentes, dantes centralizada pelo discurso médico, passa a ser relativizada por outras imagens que afirmam o papel do idoso participativo tanto social, econômica quanto afetivamente. A existência de núcleos familiares intergeracionais ou mesmo multigeracionais chefiados por idosos é um fato social percebido e retratado por diversas pesquisas de natureza qualitativa e quantitativa. Aproximar a velhice da infância, mediada pelo cuidado dos muito mais velhos com os mais novos projeta uma ponte entre as gerações.

Os resultados de pesquisas demográficas e sociológicas (IBGE, 2010) indicam uma extensão da idade produtiva, maior participação dos idosos no mercado de trabalho e como consumidores. A renda dos mais velhos vem sendo identificada como responsável pela manutenção familiar, especialmente dos mais jovens. A contraposição desta imagem com a do idoso exclusivamente dependente sugere a possibilidade da formação de um novo modelo de família, com múltiplas gerações convivendo no mesmo espaço residencial e sob outra chefia, não do adulto em idade considerada produtiva, mas a do idoso provedor.

0 presente artigo adotou uma estratégia de pesquisa de natureza qualitativa mediante revisão de literatura contemporânea nacional e estrangeira e análise de dados estatísticos do Instituto Brasileiro de Geografia e Estatística/IBGE (CENSO, PNAD e PEA). A utilização dos dados censitários, das pesquisas domiciliares e dos institutos econômicos, como estratégia metodológica, combinou a análise de pesquisas de natureza qualitativa com dados estatísticos, no que Bruschini (1989, p. 11) considerou como "a conduta mais enriquecedora em pesquisas sociológicas sobre a estrutura e a vida familiar". 


\section{ENVELHECIMENTO E O PAPEL DOS IDOSOS}

0 envelhecimento populacional, fenômeno demonstrado reiteradamente pelas pesquisas demográficas ao longo do Séc. XX e ainda dissecado por estudos econômicos, sociológicos e de diversas outras áreas do conhecimento, primordialmente neste primeiro decênio do Séc. XXI instiga uma análise crítica do papel, imagem e lócus social atual deste idoso, cada vez mais presente no convívio social.

Elucida Debert (1999), que a criação de um campo científico destinado ao estudo do envelhecimento, envolveria o discurso gerontológico apoiado em dois fundamentos: transformar a velhice em uma questão política e propor práticas para a promoção de um envelhecimento bem-sucedido. Tal discurso basear-se-ia em quatro elementos recorrentes: a iminência de uma explosão demográfica e seu reflexo no aumento dos gastos públicos para atender às demandas específicas da população idosa; a crítica ao capitalismo, que excluiria o idoso, não mais membro da classe trabalhadora; a cultura brasileira que valorizaria o novo em detrimento do velho e a crítica ao Estado Brasileiro, que, incapaz de resolver os problemas básicos da maioria da população, deixaria os idosos em situação de extrema vulnerabilidade.

A perspectiva acima identificada, também chamada de biomédica, foi responsável pela construção e fixação da imagem fragilizada e infantilizada do idoso. 0 exclusivo olhar geriátrico sobre o envelhecimento, de forma paradoxal, contribuiria para a negativação da senescência e a positivação da juventude (SILVA et al., 2004). Esse discurso, contudo, contrasta com outras imagens de idosos construídas pela mídia e também com os dados obtidos de novas pesquisas, evidenciando que as mudanças ocorridas no modus vivendi das etapas mais avançadas da vida e sua transformação em novos mercados de consumo acabaram por exigir uma reformulação da imagem do idoso (DEBERT, 1999). Neste sentido, Gaiarsa (2004), analisando anúncios publicitários desde a primeira década do Século XX, avaliou uma mudança significativa da imagem retratada do idoso. Em uma perspectiva de análise de discurso, verificou que no início do Século XX era comum a figura do idoso ser sempre relacionada às doenças, no papel daquele que anuncia ou necessita de algum medicamento, em oposição ao verificado atualmente, quando a terceira idade também é representada como o momento de iniciativa, enunciando a possibilidade de realizações, antes interditadas aos idosos.

A ideia do idoso como exclusivamente dependente, vulnerável e socialmente excluído não mais se sustentaria, e não apenas pelo fato de tal público ser cobiçado pelo mercado de consumo, mas também pelos dados obtidos nas diversas pesquisas de natureza qualitativa e quantitativa, (os últimos números do IBGE, IPEA, PNAD trazem uma expressiva quantidade de idosos como chefes de domicílio e com evidente participação no mercado de trabalho), que sugerem novas visões sobre o envelhecimento a serem provocadas e debatidas. A imagem positiva dos velhos vinculada aos anúncios de 
produtos revela a tentativa de propagar uma imagem, mas, ao mesmo tempo, representa um reflexo de um estereótipo cada vez mais comum no dia a dia das grandes cidades. Assim, os idosos que assistem a tais comerciais se identificam em um jogo ambíguo de querer e já ser.

Concernente aos dados estatísticos que identificam o idoso como provedor é importante a verificação do método utilizado pelo Censo 2000 para individualizar e quantificar tal fato social. A pesquisa estatística parte da indicação pelos moradores do domicílio da "pessoa de referência" no ambiente domiciliar, o que envolve a percepção de quem é o maior responsável, não apenas pela manutenção financeira, mas como a "referência do domicílio", o que envolve uma imagem não de fragilidade ou dependência, mas de autoridade, respeito e outros aspectos positivos. Santana, Puchain e Bissi (2002), quando da análise dos dados extraídos pelo IBGE (2000) ressaltam a indicação de 8,96 milhões de idosos pelos seus conviventes como responsáveis por domicílios, o que evidencia um aumento de 40\% em relação a 1991. Este contingente expressivo de idosos responsáveis pela manutenção do domicílio demonstram a atualidade e importância do tema.

Corroborando com a linha crescente de participação dos idosos no orçamento familiar e sua imprescindibilidade enquanto mantenedores e referência afetiva, a Síntese de Indicadores Sociais (IBGE, 2010), publicação que reúne os principais resultados da Pesquisa Nacional por Amostra de Domicílios (PNAD), em 2009, identificou 64,1\% de idosos como pessoa de referência no domicílio em que residem, bem como que, no Brasil, 10,5\% dos idosos convivem com outros parentes, que não filhos. Já a distribuição percentual do rendimento nos arranjos familiares informa que 18,8\% da renda familiar provêm de aposentadorias e pensões. Contudo, não se percebe, em tal análise, a proporção de idosos conviventes exclusivamente com crianças e adolescentes, quando não filhos, já que esta não é uma pergunta utilizada na pesquisa demográfica.

Não obstante a ausência de dado específico sobre as famílias envolvendo avós e netos, a se buscar o indicador de dependência, que, segundo a PNAD (IBGE, 2010) é indicador demográfico bastante utilizado para fins de análise socioeconômica, em 2009, pode-se aferir uma razão de 35,6\% de jovens dependentes em relação a 11,6\% de idosos na mesma condição. A dependência econômica dos jovens (entendidos na faixa etária de 0 a 24 anos de idade) é mais expressiva que a de idosos, denunciando uma tendência, em residências de convivência entre os mesmos, que os primeiros seriam em maior proporção dependentes do segundo que o inverso. 0 dado demográfico apresentado expõe uma fissura entre a imagem do idoso como o membro vulnerável da família e a realidade analisada quantitativamente, de uma porcentagem pequena, embora não irrelevante, de idosos dependentes de suas famílias. 
Os dados do IPEA sobre a população economicamente ativa, em 1998, analisados por Camarano (2001) chancelam a constatação da PNAD em uma medida de evolução histórica, já em que informam que, ainda na década de 90, o rendimento médio da população masculina idosa situava-se em um patamar mais elevado do que o da população jovem, especialmente para os idosos abaixo de 80 (oitenta) anos. A análise de Simões (2004) sobre os mesmos estudos demográficos informa que os idosos estariam em condições de vida melhores do que os segmentos mais jovens, contribuindo significativamente para renda familiar. Em pesquisa qualitativa com 68 (sessenta e oito) aposentados residentes na cidade do Rio de Janeiro, Peixoto (2004a), concluiu que os pais aposentados eram menos dependentes dos filhos e que, ao contrário, diante do aumento das taxas de desemprego e de divórcio, a casa dos pais se transformaria em um lugar de suporte socioeconômico e afetivo tanto para filhos quanto para netos.

De acordo com dados colhidos por Wajnman, Oliveira e Oliveira (2004) o resultado financeiro advindo do trabalho do idoso seria fundamental na manutenção de sua renda pessoal e familiar, não se podendo prever outros mecanismos compensatórios que possibilitem a diminuição de sua participação no mercado de trabalho. Apontam que, no grupo de idosos de 60-64 anos, o rendimento dos homens corresponderia a 67\% de sua renda familiar no meio urbano e $69 \%$ no rural, dos quais $31 \%$ seriam rendimentos do trabalho do idoso urbano e $37 \%$ do rural. Outro ponto marcante e, de certa forma surpreendente, é que não há relação entre envelhecimento e diminuição de sua participação na renda familiar, o que só ocorrerá a partir do grupo de 80 anos ou mais. No caso das mulheres, a sua participação na renda familiar é de $55 \%$ no ambiente urbano e rural.

Analisando os dados do IBGE, as autoras acima referidas alertam que há relação intrínseca entre a participação do idoso chefe de família e a renda do grupo familiar que o mesmo chefia. Assim, quanto menor seria renda familiar do idoso, maior seria a taxa de atividade deste, o que ocorre de forma mais grave com os idosos que habitam em localidades rurais e que coabitam com outros membros da família. A renda familiar do idoso que coabita com outros familiares chega a representar quase $60 \%$ do total de renda das famílias urbanas e 70\% das rurais. A problemática da relação intergeracional atinge as famílias de baixa renda de forma mais expressiva, vez que, para estas, o rendimento e o trabalho do idoso são essenciais para a sua manutenção.

A representatividade das famílias que possuem idosos como provedores também pode ser observada nos dados do IPEA, IBGE e PNAD colhidos por Camarano (2001), que atestam que, em 1998, 53\% da renda das famílias que tinham idosos provinham do rendimento destes. Porém, quando o idoso era o chefe da família, em detrimento de outros adultos, a sua renda representava $68 \%$ da renda familiar. 
Como o envelhecimento é um fenômeno mundial, a convivência em lares intergeracionais também pôde ser observada em outros países. Em estudo baseado nos dados do Censo do Canadá, em 2001, Milan e Hamm (2003) chegaram ao número de 474.400 avós que convivem com seus netos no mesmo domicílio, tanto em lares multigeracionais, como, em 12\% dos casos, sem a geração intermediária. De acordo com as autoras, cerca de $35 \%$ dos avós que vivem em domicílios multigeracionais são mantenedores do domicílio.

Segundo Camarano et al. (2004), no Brasil, entre 1980 e 2000, verificou-se um aumento das famílias chefiadas por idosos, que passaram de $17,1 \%$ para $20,9 \%$, sendo que as famílias em que o idoso é o dependente teriam reduzido tanto em termos absolutos quanto relativos, apontando para uma redução da dependência dos idosos.

As rendas aferidas pelos idosos, ao contrário do que possa parecer à primeira vista, não vêm exclusivamente do benefício previdenciário. Neves (2006) chama atenção para a posição privilegiada das avós pela capacidade de aglutinaçã̃o de diversas fontes de recursos, exemplificando algumas, como a assistência continuada, pensão ou aposentadoria, o acesso a bolsa de alimentos, a posse ou aluguel de barraco em favelas, bem como a possibilidade de redefinir os próprios estereótipos da velhice para a sua inserção social.

0 trabalho dos idosos também é uma fonte muito comum de recursos. Diversos estudos apontam para a reinserção do idoso no mercado de trabalho de forma representativa, o que é identificada pelo Instituto de Pesquisa Econômica Aplicada (IPEA, 2011) ao analisar a População Economicamente Ativa (PEA). Camarano (2001) chama atenção para o decréscimo da participação de idosos, nos períodos de 1977 a 1998, sendo que neste último ano seria de $24,2 \%$ o número de idosos que exerceriam algum tipo de participação econômica, o que independeria do crescente acesso dos idosos à Previdência Social. Apesar da redução do número de idosos na população economicamente ativa, a autora ressalta que o rendimento dos idosos assume cada vez mais importância na economia brasileira. Pode-se aferir de tais constatações, que, até 0 ano de 1998, verificar-se-ia uma diminuição no número de idosos que trabalham, contudo, a renda destes fincaria seu grau de importância na economia familiar e do país.

Os dados do IPEA (2011) sobre o mercado de trabalho, compreendendo os períodos de 2003 ao primeiro trimestre de 2011, apresentam não um decréscimo, como verificado nas décadas de 70 a 90 por Camarano (2001), mas, no sentido inverso, um aumento da taxa de participação das pessoas acima de 50 (cinquenta) anos no mercado de trabalho. Em 2003, seriam 3.272 mil cidadãos maiores de 50 (cinquenta) anos que fariam parte da população economicamente ativa, o que aumenta para $4.422 \mathrm{mil} \mathrm{em}$ 2010 e cuja trajetória permanece em ascensão no primeiro trimestre de 2011, em que se 
encontra 4.744 mil pessoas maiores de 50 (cinquenta) anos em atividade. Este contingente demonstra que a taxa de participação dos maiores de cinquenta anos é de cerca de 40\% (quarenta por cento), número que não se pode desconsiderar. Ressalte-se que, embora as pessoas aos cinquenta anos não possam ser consideradas idosas, o que, segundo o Estatuto do Idoso (BRASIL, 2003), só ocorre ao se completar 60 (sessenta) anos, a pesquisa não discrimina as faixas etárias, resumindo em igual ou maior de 50 (cinquenta) anos, o que não retira o fato do aumento do contingente de pessoas no mercado de trabalho, próximas ou dentro da chamada "idade avançada".

Na perspectiva de Camarano (2001), a volta ao mercado de trabalho seria uma característica própria da sociedade brasileira, com o nível de participação do idoso na população economicamente ativa alto, especialmente ao se comparar com os padrões internacionais. No que concorda Teixeira (2009), analisando um ponto recorrente na realidade brasileira: a permanência dos idosos no sistema produtivo, em que quase 50\% dos idosos e um terço das idosas ainda trabalham e com estas fontes de renda, mesmo quando mínimas, permitem-lhes manter e chefiar suas famílias. Este dado também é verificado por Peixoto (2004b), indicando que mais da metade da população acima de 60 (sessenta) anos ainda trabalha e um terço dos idosos aposentados ainda está inseridos no sistema produtivo.

A reinserção do idoso no mercado de trabalho é valorizada e mesmo incentivada, como esclarece Carrera-Fernandez e Menezes (2001), ao inexistir impedimento legal para que o aposentado continue ou se insira outra vez no mercado de trabalho. Pela continuidade de suas contribuições vertidas para a previdência, aumenta-se a receita do Estado, ao tempo em que se reduz o déficit previdenciário. A continuidade do idoso no mercado de trabalho, após a aposentadoria, também é estimulada por determinados seguimentos empresariais pela possibilidade de aliar experiência a baixos salários e informalidade, já que alguns aposentados,, supostamente, não mais se interessariam em contribuir para a seguridade social ou em ter a carteira assinada.

Diversos motivos podem ser atribuídos para o retorno ao mercado de trabalho, especialmente relacionados à mudança na imagem do próprio idoso, que passa a ser aceito como mão de obra produtiva. Para Peixoto (2004b), trabalhar para manter as mesmas condições de vida, por solidariedade familiar e para preencher 0 vazio social são os principais pontos de vista para se analisar o trabalho após a aposentadoria, porém, não os únicos, já que estes idosos também desejam manter um lugar de reconhecimento no núcleo familiar e na sociedade.

Este reconhecimento, exercido como poder dentro da família (e que justificaria a eleição do idoso pelos demais membros como "referência") foi verificado por Cabral (2009) que informa a importância do poder do chefe sobre os seus descendentes. 0 poder exprime-se na autonomia que desfrutam e que concedem aos filhos e netos, que lhes 
devem obediência e que constroem um importante elemento de autoestima para os idosos, que devolvem com a ideia de valorização da família, em uma troca não monetária.

No mesmo sentido, Barros (2006, p. 125) reflete que a imagem de si mesmo como provedor, negando a concepção do velho aposentado, bem como a necessidade econômica, seriam as formas encontradas por tais idosos de permanecerem no lugar de "centralidade e autoridade na família e de autonomia e independência como indivíduos". Mesmo nas famílias de baixa renda, em que os idosos estariam imersos no mesmo nível de pobreza e carência de seus parentes e/ou conviventes, o lugar familiar conquistado ainda permitiria a detenção de um saber e de recursos inatingíveis para 0 restante da família, enunciando uma posição de prestígio.

\section{O SISTEMA PREVIDENCIÁRIO E O RELACIONAMENTO INTERFAMILIAR}

As reformas previdenciárias levadas a cabo nas décadas de 90 e 2000 também podem ser consideradas um incentivo indireto ao trabalho dos idosos, na medida em que, ao diminuir consideravelmente a renda dos aposentados com a inserção de novos critérios de cálculo e coeficientes, como o fator previdenciário e a desindexação com 0 salário mínimo, importam em pressão para que os beneficiários complementem a renda necessária à sua manutenção e de sua família com o retorno à atividade.

Neste sentido, informa Peixoto (2004a) que há vários anos o sistema previdenciário não atenderia mais o seu objetivo, de proporcionar ao aposentado um nível de vida próximo ao de quando o trabalhador estava em atividade, o que explicaria o porquê de as fronteiras entre atividade e inatividade não serem mais determinadas pela aposentadoria, no Brasil.

A renda desses idosos advém de variadas fontes, como afirmado acima, sendo as principais o trabalho, a rede de assistência social, instituições filantrópicas, bem como, ocupando papel importante, a Previdência Social. Nas palavras de Santana, Pouchain e Bissi (2002, p.10), "A elevação no número de idosos responsáveis por domicílios pode ser uma das consequências da garantia de renda proporcionada pelos benefícios previdenciários."

Apesar das deficiências do sistema previdenciário, especialmente vinculadas à perda do poder de compra em relação ao salário mínimo, percebe-se a participação da Previdência Social como um dos essenciais fatores para a assunção dos idosos da responsabilidade pela manutenção financeira de suas famílias, mas não a única, como acima demonstrado. 
Segundo o Ministério da Previdência Social (BRASIL, 2010), baseando-se em dados da PNAD, os benefícios pagos pela Previdência Social produzem impactos significativos sobre o nível de pobreza da população brasileira. Observa-se que, caso fossem desconsideradas as rendas advindas do recebimento de benefícios previdenciários, a quantidade de pobres seria de 78,26 milhões de brasileiros, sendo o plano de benefícios da Previdência Social o responsável pela retirada da condição de pobreza de cerca de 23,13 milhões de brasileiros.

Ainda segundo análise do Brasil (2010) os idosos socialmente protegidos - que recebem aposentadoria e/ou pensão de qualquer regime previdenciário ou da assistência social ou contribuem para a Previdência Social - totalizariam 16,1 milhões de pessoas, sendo 7,6 milhões homens e 8,5 milhões mulheres. A importância da Previdência Social para a manutenção familiar constata-se pela redução de pobreza em todas as faixas etárias, que são direta e indiretamente afetadas, sendo que a pobreza diminui com 0 aumento da idade (quando passam a ser diretamente beneficiárias), chegando ao limite inferior de 10\% para a população com 70 anos de idade ou mais.

Estes idosos, segurados e provedores, não podem ser imediatamente considerados como modelos representativos da velhice no Brasil, assim como a análise dos números demográficos não deve servir de argumento para a diminuição de assistência social ou programas de inserção e recuperação de renda para idosos dependentes. 0 momento é do olhar a este ator político, parte de relações sociais heterogêneas, envolvido em uma multiplicidade de aspectos. Nas palavras de Debert (1999, p. 230): "0 idoso como ator político converteu a solidariedade entre gerações e a dimensão moral das políticas em uma questão central de cidadania”. Assim, a verificação de uma nova velhice, não significa negar a existência da velhice dependente, com todas as suas complexas questões de vulnerabilidade e necessidade de políticas públicas específicas.

Neste sentido, Silva et al. (2004, p. 3), alertam para a produção de conhecimento que evidencie a passagem de uma concepção reducionista sobre a velhice para uma concepção "relativista, humanista, interdisciplinar e plural", pondo em cena uma plêiade de imagens de idosos (as) diferenciados e em todos os seus aspectos, seja o idoso demenciado, dependente, autônomo, educador, narrador, militante ou mesmo feliz.

Estudos na área de psicologia ressaltam que o trabalho seria essencial para a qualidade de vida dos idosos, influenciando no seu desenvolvimento físico, cognitivo e emocional. (NASCIMENTO, ARGIMON; LOPES, 2006). 0 exercício do trabalho não deixa de conter uma contradição, estando o idoso-trabalhador muitas vezes dividido entre 0 legítimo direito ao descanso e a o status de inferioridade decorrente da inatividade (DELGADO, 2009).

No presente estudo não se pretende avançar em tais questionamentos, envolvendo a disputa do lócus e privilégios entre classes sociais, mas no pensamento sobre 
mudanças da imagem do idoso decorrentes no maciço envelhecimento populacional e da sua reinserção no mercado de trabalho, o que efetivamente ocorre seja no sistema produtivo formal ou informal, ou mesmo como garantidor de renda à sua família pelo recebimento de benefícios previdenciários. Assim, nem o envelhecimento marginalizado pelas restrições dos papéis sociais, (produtivos e familiares) que geram depressão, solidão e isolamento, nem o seu inverso, do envelhecimento como a melhor fase da vida, idade do prazer, do lazer, das realizações, caracterizam por completo a velhice, interditando análises generalizantes.

Estudos (CAMARANO, 2001; CARRERA-FERNANDES; MENEZES, 2001; WAJMAN; OLIVEIRA; OLIVEIRA, 2004) ainda ressaltam que quando se tratam de idosos de baixa renda, o fator gênero e cor ainda são mais preponderantes em relação ao valor dos rendimentos, bem como a sua importância no orçamento familiar.

A questão de gênero também não se encontra alijada da relação entre envelhecimento, família e sua manutenção, especialmente quando o número de idosas provedoras apresenta-se de forma mais pujante que a de idosos. Cabral (2009) informa que, em se tratando de solidariedade familiar, especialmente urgente diante da omissão do Estado em proteger os mais carentes, o último "refúgio" desta população seria a família e nesta, sobre as mulheres, a quem são atribuídas as maiores obrigações e cuidados.

Attias-Donfut (2004) apresenta como resposta à participação feminina mais expressiva no cuidado com seus descendentes, o papel tradicional das mulheres, que teria sido ampliado com o aparecimento de uma geração chamada de "pivô", que ajudaria, ao mesmo tempo, os pais idosos, os filhos e os netos. Para Motta (2004), em virtude do desemprego estrutural ou mesmo da precariedade do trabalho, as mulheres viúvas seriam os mais frequentes esteios familiares, responsáveis pela manutenção das famílias com suas pensões e aposentadorias, este dado também foi observado por Camarano et al. (2004).

Ao tratar dos trabalhadores idosos em Juiz de Fora, Delgado (2009) relata que a experiência dos velhos aposentados dialoga com a efetividade da relação entre 0 direito ao trabalho e ao descanso e a atual estruturação dos modos de vida. Esta geração vive uma assunção de direitos que seus pais não usufruíram e que seus descendentes veem com incerteza, no contexto de crise dos sistemas de proteção trabalhista e social.

A análise dos dados acima referidos de participação ativa do idoso no mercado de trabalho e da importância de suas rendas na manutenção de suas famílias afirma uma nova visão do idoso, como não apenas o beneficiário de políticas públicas, mas como agente social de mudança e proteção. Entendendo a inserção dos idosos no mercado de trabalho, na Previdência Social e, via de consequência, nas chefias de família, percebe-se 
que as formações familiares de que trata o presente estudo também ocuparão, cada vez mais, um espaço quantitativo relevante na sociedade.

\section{ESTADO E FAMÍLIA: O PAPEL DA PROTEÇÃO ESTATAL}

A destinação das políticas públicas teve, especialmente a partir do marco constitucional, como foco, a família, não sem uma tensão evidente com a outorga de deveres estatais a esta família. Mioto (2008) ressalta que a família ocupa um lugar central tanto programas assistenciais de transferência de renda, como no campo das políticas públicas de seguridade social, especialmente na saúde e assistência social. As crianças, adolescentes e suas famílias, entendidos como sujeitos de direitos, passam a objeto e destinatários das políticas sociais, ao mesmo tempo, em que são as famílias consideradas agentes desta política, ocupando um lugar de centralidade tanto no texto do Estatuto da Criança e do Adolescente (ECA) quanto nos ordenamentos da assistência. (MOREIRA, 2010).

0 Estado intervém mais da família, na medida em que esta é o "gatilho" da política pública, imputando a esta a responsabilidade pelo cuidado, proteção e manutenção dos seus entes mais vulneráveis (atribuição expressamente prevista no art. 226 da Constituição Federal de 1988). 0 mesmo Estado devolve pouca assistência na forma de prestações, especialmente em se tratando de seguridade social.

A característica de suporte dos membros ante a insuficiência ou ineficiência do Estado é também observada por Petrini (2007), sendo esta chamada, em muitas oportunidades, como parceira da administração pública, para enfrentar problemas relativos à saúde, educação, segurança, de forma especial em relação à população de baixa renda.

A estratégia adotada pelo Estado para o enfrentamento da "questão social" é a diminuição substancial e constante da proteção social pública, com o incentivo à mobilização de recursos informais vinculados a uma solidariedade familiar primária, para que esta e a comunidade em geral tomem para si o papel de transmissores de recursos. (DELGADO, 2009). Haveria um descompasso, alertado por Rizzini et al. (2007) na importância atribuída ao papel da família no discurso e a falta de condições de vida digna para que estas possam criar seus filhos, sendo mais "fácil" identificar a negligência cometida pelos pais ao se encontrar uma criança "em situação de risco" do que acusar o Estado de negligência e omissão.

Com a prevalência das políticas sociais visando o enxugamento do Estado, as famílias são instadas a cuidar de seus segmentos mais vulneráveis, utilizando para isto diversas ferramentas como o apoio intergeracional e a co-residência (CAMARANO et al., 2004). Essa consideração vai de encontro aos estudos que relacionam a escassez de 
recursos financeiros da geração intermediária, com a formação das famílias "de idosos", ou seja, famílias em que o idoso é o responsável pela manutenção da residência.

No seio dessa família intergeracional, pode-se verificar a diminuição da participação do Estado como devedor dos direitos sociais mais essenciais, especialmente em relação às crianças, em detrimento das famílias. É exatamente o que ressalta Carvalho (2010) quando, em um contexto de crise do "welfare state", ressurge a família e a comunidade como unidade econômica e direito da criança, com quem o Estado partilha as responsabilidades e os custos das políticas públicas de proteção e reprodução de seus cidadãos.

A postura estatal atinge em cheio a família pobre, diante das próprias dificuldades econômicas e impossibilidade de acesso a recursos diversos. Atuaria o Estado em uma vertente dúplice, propagandeando a importância do reforço aos laços familiares e comunitários e, nesta esteira, responsabilizando a família, bem como, de forma diametralmente oposta, intervindo nesta sob o prisma da dissolução dos vínculos sociais nos meios populares em função da violência e pobreza. Também atuaria o Estado de forma paradoxal quando estabelece o dever de cuidado da família para com as suas crianças, porém, na ausência desta, nega a proteção básica, da seguridade social.

A autodeterminação dos idosos possibilita a reafirmação dos valores familiares e a transmissão de conhecimentos aos seus descendentes. É a solidariedade familiar e 0 apoio intergeracional, mais que a participação direta do Estado na integração das crianças e adolescentes a um núcleo familiar sadio e autossustentável, que possibilita aos netos, convivendo sob a responsabilidade formal e informal dos seus avós, uma sobrevivência digna e o cumprimento de seu desenvolvimento saudável.

Esta relação familiar, negligenciada pela ausência de uma política pública específica voltada para estes lares intergeracionais, acaba por se desenvolver nas teias sociais, não obstante todas as limitações físicas e financeiras que cercam a velhice, possibilitando sobrevivência e proteção dos mais vulneráveis.

\section{REFERÊNCIAS}

ATTIAS-DONFUT, Claudine. Sexo e envelhecimento. In: PEIXOTO, Clarice Ehlers (Org.). Familia e envelhecimento. Rio de Janeiro: Editora FGV, 2004.

BARROS, Myriam Moraes Lins de. Trajetória dos estudos de velhice no Brasil. Sociologia, Problemas e Práticas, Lisboa, n. 52, 2006.

BEHRING, Eliane Rossetti; BOSCHETTI, Ivanete. Política social: fundamentos e história. São Paulo: Cortez, 2006. 
BRASIL. Lei n. 10.741, de 1 de outubro de 2003. Dispõe sobre o estatuto do idoso e dá outras providências. Disponível em:

<http://www.planalto.gov.br/ccivil_03/leis/2003/L10.741.htm>. Acesso em: 23 mar. 2011.

BRASIL. Ministério da Previdência Social. Evolução recente da proteção previdenciária e seus impactos sobre o nível de pobreza. Informe de Previdência Social, Brasília, v. 22, n. 10, out. 2010. Disponível em: <http://www.mpas.gov.br/arquivos/office/4_101130153918-908.pdf>. Acesso em: 23 mar. 2011.

BRUSCHINI, Cristina. Uma abordagem sociológica de família. Revista Brasileira de Estudos da População, São Paulo, v. 6, n. 1, p. 1-23, jan./jun. 1989. Disponível em $<$ http://www.abep.nepo.unicamp.br/docs/rev_inf/vol6_n1_1989/vol6_n1_1989_1artig 0_1_23.pdf >. Acesso em: 13 mar. 2011.

CABRAL, Benedita Edina S. Lima. Longevidade e permanência das desigualdades de gênero e geração na família Contemporânea. In: CONGRESSO BRASILEIRO DE SOCIOLOGIA, 14., 2009, Rio de Janeiro. Anais... Rio de Janeiro: Sociedade Brasileira de Sociologia. Disponível em <http://starline.dnsalias.com:8080/sbs/arquivos/15_6_2009_17_15_20.pdf>. Acesso em: 3 abr. 2011.

CAMARANO Ana Amélia et al. Famílias: espaço de compartilhamento de recursos e vulnerabilidades. In: CAMARANO, Ana Amélia (Org). Os novos brasileiros: muito além dos 60? Rio de Janeiro: IPEA, 2004. p. 137-167.

CAMARANO Ana Amélia. O idoso brasileiro no mercado de trabalho. Rio de Janeiro: IPEA, 2001.

CARRERA-FERNANDEZ, José; MENEZES, Wilson. 0 idoso no mercado de trabalho: uma análise a partir da região metropolitana de Salvador. Revista Econômica do Nordeste, Fortaleza, 2001. Disponível em:

$<$ http://www.sei.ba.gov.br/images/releases_mensais/pdf/ped/ped_estudos_especiais/ido so_mercado_trabalho.pdf>. Acesso em: 5 ago. 2011.

CARVALHO, Maria do Carmo Brant. A priorização da família na agenda da política social. In: KALOUSTIAN, Silvio Manoug (Org.). Familia brasileira, a base de tudo. 9. ed. São Paulo: Cortez, 2010. p. 93-108.

DEBERT, Guita Grin. A reinvenção da velhice: socialização e processos de reprivatização do envelhecimento. São Paulo: Edusp/Fapesp, 1999.

DELGADO, Josimara. Contemporaneidade e costume: reflexões sobre gerações, famílias e trabalho. In: CONGRESSO BRASILEIRO DE SOCIOLOGIA: CONSENSOS E CONTROVÉRSIAS, 14., 2009, Rio de Janeiro. Anais... Rio de Janeiro: Sociedade Brasileira 
de Sociologia, 2009. Disponível em:

$<$ http://starline.dnsalias.com:8080/sbs/arquivos/15_6_2009_17_15_20.pdf > . Acesso em: 3 abr. 2011.

GAIARSA, Maria Amélia Chagas. A imagem do idoso na publicidade brasileira: uma retrospectiva. In: JACQUET, Christiane; COSTA Lívia Fialho. Familia em mudança. São Paulo: Companhia Ilimitada, 2004.

IBGE. Pesquisa nacional por amostra de domicilios: síntese de indicadores 2009. Rio de Janeiro: IBGE, 2010. Disponível em:

$<$ http:/www.ibge.gov.br/home/estatistica/populacao/trabalhoerendimento/pnad2009/p nad_sintese_2009.pdf>. Acesso em: 23 abr. 2011.

IPEA. Boletim Mercado de Trabalho: conjuntura e análise, n. 47, maio 2011.

Disponível em: < http://www.ipea.gov.br/082/08201002.jsp?ttCD_CHAVE=3422>. Acesso em: 7 ago. 2011.

MILAN, Anne Milan; HAMM, Brian. Le liens entre les générations: grand-parents et petitsenfants. Tendances Sociales Canadiennes, Statistique Canada, n. 11, 2003. Disponível em: <http://www.statcan.gc.ca/studies-etudes/11-008/feature-caracteristique/5024065fra.pdf>._Acesso em: 7 ago. 2011.

MIOTO, Regina Celia Tamaso. Família e políticas sociais. In: BEHRING, Eliane Rossetti et al. Política social no capitalismo: tendências contemporâneas. São Paulo: Cortez, 2008. p 130-148.

MOREIRA, Maria Ignez Costa. As desigualdades sociais e a produção da judicialização da infância e da adolescência no Brasil. In: MAYORGA, Claudia; PEREIRA, Maristela; RASERA, Emerson (Org.). Psicologia social: sobre desigualdade e enfrentamentos. Curitiba: Juruá, 2010.

MOTTA, Alda Brito. Relações. Sociabilidades possíveis: idosos e tempo geracional. In: PEIXOTO, Clarice Ehlers (Org.). Familia e envelhecimento. Rio de Janeiro: Editora FGV, 2004. p. 109-144.

NASCIMENTO, Roberta Fernandes Lopes; ARGIMON, Irani I. de Lima; LOPES, Regina Maria Fernandes. Atualidades sobre o idoso no mercado de trabalho. 2006. Disponível em: <http://www.psicologia.pt/artigos/textos/A0300.pdf>. Acesso em: 1 abr. 2010.

NEVES, Delma Pessanha. As idosas provedoras e o enraizamento familiar. In: FONSECA, Cláudia; BRITES, Jurema (Org.). Etnografias da participação. Santa Cruz do Sul: EDUNISC, 2006.p. 359-379.

PEIXOTO, Clarice Ehlers. Aposentadoria: retorno ao trabalho e solidariedade familiar. In: . Familia e envelhecimento. Rio de Janeiro: Editora FGV, $2004 a$. 
Trabalhando sempre: aposentados que se reinserem no mercado de trabalho e apoio familiar. In: JACQUET, Christine; COSTA Lívia Fialho (Org.). Familia em mudança. São Paulo: Companhia Ilimitada, 2004b.

PETRINI, João Carlos. Políticas sociais dirigidas à família. In: BORGES, Ângela; CASTR0, Mary Garcia (Org.). Familia, gênero e gerações: desafios para as políticas sociais. São Paulo: Paulinas, 2007.

RIZZINI, Irene (Coord.) et al. Acolhendo crianças e adolescentes: experiências de promoção de direito à convivência familiar e comunitária no Brasil. 2. ed. São Paulo: Cortez, 2007.

SANTANA, Rafael Liberal Ferreira; POUCHAIN, Geise de Castro; BISSI, Luciano Fávaro. Previdência social e o censo 2000: perfil dos idosos. Informe de Previdência Social, Brasília, v.14, n. 9, set. 2002. Disponível em:

<http://mpas.gov.br/arquivos/office/3_081014-104628-214.pdf>. Acesso em: 23 mar. 2011.

SILVA, Keila Queiroz et al. 0 (a) Idoso (a): uma face e uma voz interditadas pela família e pela escola em Campina Grande. In: CONGRESSO BRASILEIRO DE EXTENSÃO UNIVERSITÁRIA, 2., 2004, Belo Horizonte. Anais... Belo Horizonte, 2004. Disponível em: http://www.google.com.br/url?sa=t\&rct=j\&q=\&esrc=s\&source=web\&cd=1\&cad=rja\& ved=0CDAQFjAA\&url=http\%3A\%2F\%2Fwww.ufmg.br\%2Fcongrext\%2FEduca\%2FWORD \%2FEduca125a.doc\&ei=HButUIzbDpSm8gTs1YGgAQ\&usg=AFQjCNFSr7DYxEa7290gmj AMr0SgXusZrQ > . Acesso em: 5 abr. 2011.

SIMÕES, Júlio Asses. Provedores e militantes: imagens de homens aposentados na família e na vida pública. In: PEIXOTO, Clarice Ehlers (Org.). Familia e envelhecimento. Rio de Janeiro: Editora FGV, 2004.

TEIXEIRA, Solange Maria. Envelhecimento do trabalhador e as tendências das formas de proteção social na sociedade brasileira. Argumentum, Vitória, v. 1, n. 1, jul./dez. 2009.

WAJNMAN, Simone; OLIVEIRA, Ana Maria H. C.; OLIVEIRA, Elzira Lúcia de Os idosos no mercado de trabalho: tendências e consequências. In: CAMARANO, Ana Amélia (Org.). Os novos idosos brasileiros: muito além dos 60? Rio de Janeiro: IPEA, 2004. p. 453-479. Disponível em: <www.ipea.gov.br/sites/000/2/.../idososalem60/Arq_23_Cap_14.pdf>. Acesso em: 7 fev. 2011. 